\title{
Obstructive sleep apnoea in the elderly: role of continuous positive airway pressure treatment
}

\author{
Miguel Ángel Martínez-García ${ }^{1,2}$, Eusebi Chiner ${ }^{3}$, Luis Hernández ${ }^{4}$, \\ Jose Pascual Cortes ${ }^{5}$, Pablo Catalán ${ }^{6}$, Silvia Ponce ${ }^{7}$, Jose Ramón Diaz ${ }^{8}$, \\ Ester Pastor ${ }^{9}$, Laura Vigil ${ }^{10}$, Carmen Carmona ${ }^{2,11}$, Josep Maria Montserrat ${ }^{12}$, \\ Felipe Aizpuru ${ }^{13}$, Patricia Lloberes ${ }^{14}$, Mercedes Mayos ${ }^{15}$, Maria José Selma ${ }^{1}$, \\ Jose Fernando Cifuentes ${ }^{1}$ and Alvaro Muñoz ${ }^{1}$ on behalf of the Spanish Sleep \\ Network ${ }^{16}$
}

Affiliations: ${ }^{1}$ Respiratory Dept, Hospital Universitario y Politécnico La Fe, Valencia, Spain. ${ }^{2}$ CIBER Enfermedades Respiratorias (CibeRes) (CB06/06), Bunyola, Spain. ${ }^{3}$ Respiratory Dept, Hospital Universitario San Juan, Alicante, Spain. ${ }^{4}$ Respiratory Dept, Hospital General Universitario, Alicante, Spain. ${ }^{5}$ Respiratory Dept, Hospital La Plana, Castellón, Spain. ${ }^{6}$ Respiratory Dept, Hospital General Requena, Valencia, Spain. ${ }^{7}$ Respiratory Dept, Hospital Universitario Peset, Valencia, Spain. ${ }^{8}$ Respiratory Dept, Hospital Universitario, Castellón, Spain. ${ }^{9}$ Respiratory Dept, Hospital Torrevieja, Alicante, Spain. ${ }^{10}$ Respiratory Dept, Hospital de Sabadell, Corporació Sanitaria Parc Tauli, Barcelona, Spain. ${ }^{11}$ Respiratory Dept, Hospital Universitario Virgen del Rocio, Sevilla, Spain. ${ }^{12}$ Respiratory Dept, IDIBAPS-Hospital Clinic, Barcelona, Spain. ${ }^{13}$ Araba Health Research Unit, BioAraba, Osakidetza, Vitoria, Spain. ${ }^{14}$ Respiratory Dept, Hospital Universitario Vall Hebrón, Barcelona, Spain. ${ }^{15}$ Respiratory Dept, Hospital Universitario Santa Creu i Sant Pau, Barcelona, Spain. ${ }^{16}$ For members of the Spanish Sleep Network, see the Acknowledgements section.

Correspondence: Miguel Ángel Martínez-García, Servicio de Neumología, Hospital Universitario y Politécnico La Fe, Valencia, Bulevar Sur s/n, 46026 Valencia, Spain. E-mail: mianmartinezgarciađagmail.com

ABSTRACT Almost all the information about the effect of continuous positive airway pressure (CPAP) in patients with obstructive sleep apnoea (OSA) comes from clinical trials involving only middle-aged patients. The objective of this study was to assess the effect of CPAP treatment in elderly patients with severe OSA on clinical, quality-of-life and neurocognitive spheres.

We performed an open-label, randomised, multicentre clinical trial in a consecutive clinical cohort of 224 elderly $(\geqslant 70$ years old) patients with confirmed severe OSA (apnoea-hypopnea index $\geqslant 30$ ) randomised to receive CPAP $(n=115)$ or no CPAP $(n=109)$ for 3 months. A sleep study was performed by either full polysomnography or respiratory polygraphy. CPAP titration was performed by an autoCPAP device. The primary endpoint was quality of life (Quebec Sleep Questionnaire) and secondary endpoints included sleeprelated symptoms, presence of anxiety/depression, office-based blood pressure and some neurocognitive tests.

The mean \pm SD age was $75.5 \pm 3.9$ years. The CPAP group achieved a greater improvement in all qualityof-life domains $(\mathrm{p}<0.001$; effect size: $0.41-0.98)$, sleep-related symptoms $(\mathrm{p}<0.001$; effect size $0.31-0.91)$ as well as anxiety $(p=0.016$; effect size 0.51$)$ and depression $(p<0.001$; effect size: 0.28$)$ indexes and some neurocognitive tests (digit symbol test ( $\mathrm{p}=0.047$; effect size: 0.20$)$ and Trail Making Test A ( $\mathrm{p}=0.029$; effect size: 0.44$)$ ) in an intention-to-treat analysis.

In conclusion, CPAP treatment resulted in an improvement in quality of life, sleep-related symptoms, anxiety and depression indexes and some neurocognitive aspects in elderly people with severe OSA.

@ERSpublications

CPAP is effective in elderly patients with severe OSA in clinical and neurocognitive terms improving quality of life http://ow.ly/KHfh9

Editorial comment in Eur Respir J 2015; 46: 13-15 [DOI: 10.1183/09031936.00039915]

Received: April 042014 | Accepted after revision: Feb 102015 | First published online: May 292015

Clinical trial registered with www.clinicaltrials.gov (NCT02069600)

Copyright $\odot$ ERS 2015 


\section{Introduction}

Continuous positive airway pressure (CPAP) is the treatment of choice for symptomatic or severe obstructive sleep apnoea (OSA). However, all the published clinical trials on the effect of CPAP have included only middle-aged subjects [1-3]. Taking into account the positive results of these clinical trials, it is standard practice to treat elderly patients with sleep apnoea with CPAP [4], even though some authors have observed that the impact of OSA and treatment with CPAP in the elderly can be different from that found in younger people $[5,6]$ and that the number of sleep respiratory disorders increases in the physiological aspect, often making it difficult to distinguish the boundary between the physiological and the pathological $[7,8]$.

The population pyramid is changing, and the percentage of elderly patients is progressively increasing in industrialised countries [9]. This means that the diagnosis and treatment of OSA in the elderly have become increasingly common in sleep units [4]. However, only very limited data are currently available with respect to the effectiveness of CPAP treatment in this age group, apart from merely observational studies that seem to indicate that treatment with CPAP could be beneficial in the cardiovascular and neurocognitive spheres $[10,11]$. The hypothesis of our study is that CPAP is an effective treatment in elderly patients with severe OSA, so our main objective was to analyse the effectiveness of CPAP treatment in a group of elderly patients referred to sleep units due to clinical suspicion of OSA.

\section{Methods}

Design overview and setting

This was an open-label, randomised, multicentre clinical trial of parallel groups with a blinded end-point design, conducted in 12 clinical centres in Spain in elderly patients sent to sleep laboratories because of clinical suspicion of OSA, and diagnosed with severe OSA. Patients were randomly assigned to either CPAP or no therapy for 3 months. The study was approved by the Ethics Committee of each participating centre. All the participants provided informed signed consent. The study's quality was evaluated according to the Consolidated Standards of Reporting Trials (CONSORT) items, following the recommendations for improving the quality of reports of randomised clinical trials.

\section{Participants}

Patients were consecutively recruited from the sleep laboratories of the participating centres. Patients were initially eligible for participation in the study if they were aged $\geqslant 70$ years and had an apnoea-hypopnoea index $(\mathrm{AHI}) \geqslant 30$. Exclusion criteria included current use of CPAP treatment, central sleep apnoea (defined as at least $50 \%$ of respiratory events having a pattern of apnoea or hypopnoea without respiratory effort), respiratory failure (defined as diurnal oxygen saturation below 90\%), severe heart failure (New York Heart Association functional class III-IV), a cardiovascular event in the month prior to the inclusion in the study, disabling hypersomnia (Epworth Sleepiness Scale $(E S S) \geqslant 18$ ) and previous severe impairment of cognitive performance that, in the opinion of the researchers, ruled out their inclusion in the study.

\section{Procedures}

Sleep study

We followed the Spanish Society of Pneumology and Thoracic Surgery guidelines for diagnosis and treatment of OSA [12]. Every participant was subjected to a sleep study, either full standard polysomnography (PSG) or respiratory polygraphy (RP) with a device previously validated against PSG (Embletta Gold; Embla, Amsterdam, The Netherlands) [13]. PSG included continuous recording of electro-encephalogram, electro-oculogram, electro-myogram, electro-cardiogram, evaluations of the nasal airflow, thoracic and abdominal band movements, and arterial oxygen saturation $\left(\mathrm{S}_{\mathrm{aO}} \mathrm{O}_{2}\right)$, according to standard criteria [14]. RP included continuous recording of oronasal flow and pressure, heart rate, thoracic and abdominal respiratory movements and $\mathrm{SaO}_{2}$. All the patients undergoing $\mathrm{RP}$ who showed recording artefacts, discrepancy between the result of the RP and the pretest clinical probability (pretest clinical suspicion) of sleep apnoea (especially in patients with high pretest probability and unaltered RP results), predominance of central events or subjective sleep time of $<3 \mathrm{~h}$ had a full PSG. All data were recorded manually by the investigators. Apnoea was defined as interruption ( $>90 \%)$ of oronasal airflow for $\geqslant 10 \mathrm{~s}$, and it was classified as obstructive or central, depending on whether respiratory effort was present or absent. Hypopnoea was defined as a $30-90 \%$ reduction in the oronasal airflow for $\geqslant 10 \mathrm{~s}$ associated with a

Conflict of interest: Disclosures can be found alongside the online version of this article at erj.ersjournals.com

Support statement: The study received a grant from the Instituto de Salud Carlos III (PI11 /01892), and Linde HealthCare, Oximesa, Vitalaire and Teijin. None of these institutions played any role in the objectives, methods, data analysis or conclusions of the study. 
desaturation of $\geqslant 3 \%$ (and/or an arousal in the case of a PSG study). The AHI was defined as the number of apnoeas plus hypopneas per hour of sleep (PSG) or recording (RP).

\section{Initial visit}

At the initial visit after the sleep study, all the patients completed a standardised protocol that included general and anthropometric data, personal history especially related to cardiovascular, depression, anxiety or other neurocognitive diseases, current medication and clinical history related to OSA, including chronic snoring, witnessed apnoeas, daytime hypersomnolence, nightmares, choking, and nocturia. Nocturia was measured as the average number of times the patients woke up to go to the toilet during the night in the 15 days prior to each medical visit. The ESS was used to quantify daytime somnolence.

All patients completed a specific sleep-related quality-of-life questionnaire: the validated Spanish-language version of the Quebec Sleep Questionnaire (QSQ). The QSQ includes the quantification of diurnal and nocturnal symptoms, hypersomnolence and social interactions and emotional aspects [15, 16]. Cognitive function was assessed by an extensive neuropsychological battery administered at the same time of day in each evaluation $(09: 00 \mathrm{~h})$ by trained, blinded personnel; this covered subjective sleepiness, executive function, visual attention, speed of processing and mental flexibility (Trail Making Test (TMT) A and B) [17], working memory (digit symbol and digit span tests) [18] and symptoms of anxiety or depression (hospital anxiety and depression tests) [19]. Finally, three office-based blood pressure measurements were taken, following international recommendations [20].

\section{Random allocation}

Patients with an AHI $\geqslant 30$ were eligible for randomisation. The clinician responsible used specific software to determine the allocation groups for the patients. Random allocation stratified by site was used, without any other restriction. The software only revealed the allocation group when an investigator provided the data of a fully eligible patient, which guaranteed the concealment of the randomisation sequence.

\section{CPAP pressure titration}

In those patients randomised to CPAP treatment, optimal CPAP pressure was titrated in the sleep laboratory on a second night by an auto-CPAP device or PSG within a period of $<15$ days after the diagnosis, according to a previous validation by the Spanish Sleep and Breathing Group [21]. The optimal pressure was determined, based on the visual evaluation of the raw data recording from the night study, with no significant leaks $\left(<0.40\right.$ leaks $\left.\cdot \mathrm{s}^{-1}\right)$. This fixed pressure was then maintained throughout the study in those patients assigned to the CPAP arm.

\section{Follow-up}

Treatment with CPAP was continued for 3 months, during which the patient (with or without CPAP) had direct contact with the research team at all times for the solution of clinical problems or doubts related to the study. Medical appointments were scheduled for all patients (with or without CPAP) at 4 and 12 weeks after randomisation to ensure the same number of medical visits in all patients. Every medical appointment involved protocol-based assessments of the following: adherence to CPAP and side effects (for CPAP group) and changes in treatment and reevaluation of the exclusion criteria (for all the patients included). At the last medical appointment, after 12 weeks of treatment, all the patients again completed a standardised protocol that included sleep-related symptoms, neurocognitive battery tests, QSQ and blood pressure measurements taken at the same time as the prerandomisation tests. Adherence to CPAP was always objectively assessed by reading the device's time counter from the start of treatment to the end of follow-up. Patients were classified as being adequately treated with CPAP if treatment had been started and the average cumulative adherence was $\geqslant 4 \mathrm{~h} \cdot$ day $^{-1}$.

\section{Statistical analysis}

Normality of continuous variables was assessed by the Kolmogorov-Smirnov test and then described as mean \pm SD. Mean \pm SD was used to express normally distributed data and median (interquartile range) (TMT $\mathrm{A}$ and $\mathrm{B}$ variables) was used for non-normally distributed data. Categorical variables were reported as absolute values and percentages. The primary endpoint was the change in Quality of Life questionnaire domains (QSQ) from baseline to 3 months of CPAP or no CPAP. Secondary endpoints included sleep-related clinical changes, changes in neurocognitive tests and changes in office-based blood pressure measurements. The sample size was calculated on the basis of a clinically significant improvement in all the domains of the QSQ, using the domain that needed the largest sample size, which was social interactions, assuming an alpha error of 5\%, and a statistical power of $80 \%$, with a result of 102 patients needed per randomised arm. 
The intra-group differences from the beginning to the end of the study were evaluated with the paired t-test, and the primary objective, the inter-group comparison of the change in quality of life, was assessed by analysis of covariance (ANCOVA). The effect size was estimated by dividing this difference by the standard deviation of the baseline measurement. As proposed by CoHEN [22], an effect size of 0.20, 0.50 and 0.80 were considered as small, medium and large, respectively. The analysis was performed according to the intention-to-treat principle. Missing values of the primary endpoint were imputed under the assumption of missing at random mechanism of missingness, and taking into account baseline values. Correlation between quantitative variables was analysed using the Pearson test. A p-value $<0.05$ was considered as significant.

\section{Results}

Of the initial 285 recruited patients, 224 were randomised, 115 to the CPAP arm and 109 to the no CPAP (fig. 1). No statistical or clinical differences were observed between randomised groups (table 1). Mean \pm SD age was $75.5 \pm 3.9$ years; 153 (68.3\%) patients were men; mean \pm SD body mass index (BMI) was 32.9 $\pm 6.3 \mathrm{~kg} \cdot \mathrm{m}^{-2}$; mean \pm SD AHI was $50.4 \pm 14.9$ events $\cdot \mathrm{h}^{-1}$ (96\% of events were obstructive); $37.7 \%$ showed an $\mathrm{ESS} \geqslant 10$. No patient had central sleep apnoea.

The average use of CPAP treatment was $4.9 \pm 2.5 \mathrm{~h} \cdot$ night $^{-1}$, with $35(30.4 \%)$ patients presenting $<4 \mathrm{~h}$ per night $\left(69.6 \%\right.$ with good adherence). The mean CPAP pressure used was $8.9 \pm 1.9 \mathrm{cmH}_{2} \mathrm{O}$. The residual AHI following the application of CPAP during the titration study was $3.9 \pm 7.4$ events $\cdot \mathrm{h}^{-1} .68 .5 \%$ of studies were performed using an RP. Nine patients needed a pressure titration by attended PSG because the autoCPAP titration was not adequate. No change in BMI was observed between randomised groups over the course of the study ( $32.9 \pm 6.3$ versus $33.1 \pm 6.2 \mathrm{~kg} \cdot \mathrm{m}^{-2}$; p-value was nonsignificant).

\section{Effect on quality of life and sleep-related symptoms}

There was a significant improvement in all sleep-related symptoms, including snoring, witnessed apnoeas, choking, nightmares, daytime hypersomnolence (all $\mathrm{p}<0.001)$ and nocturia $(\mathrm{p}=0.049)$, in the CPAP group (table 2). On the other hand, all QSQ domains significantly improved in the CPAP group (all $\mathrm{p}<0.001$; table 3). CPAP use showed a moderate correlation with changes in the diurnal symptom, nocturnal symptom and emotional domains of QSQ but not with the social and hypersomnolence domains (fig. 2).

\section{Effect on anxiety and depression scores}

$52(23.2 \%)$ patients scored $\geqslant 11$ points in Hospital Anxiety and Depression Scale (HADS) depression and $38(17 \%)$ patients scored $\geqslant 11$ points in HADS anxiety. Table 4 shows that the CPAP group achieved a

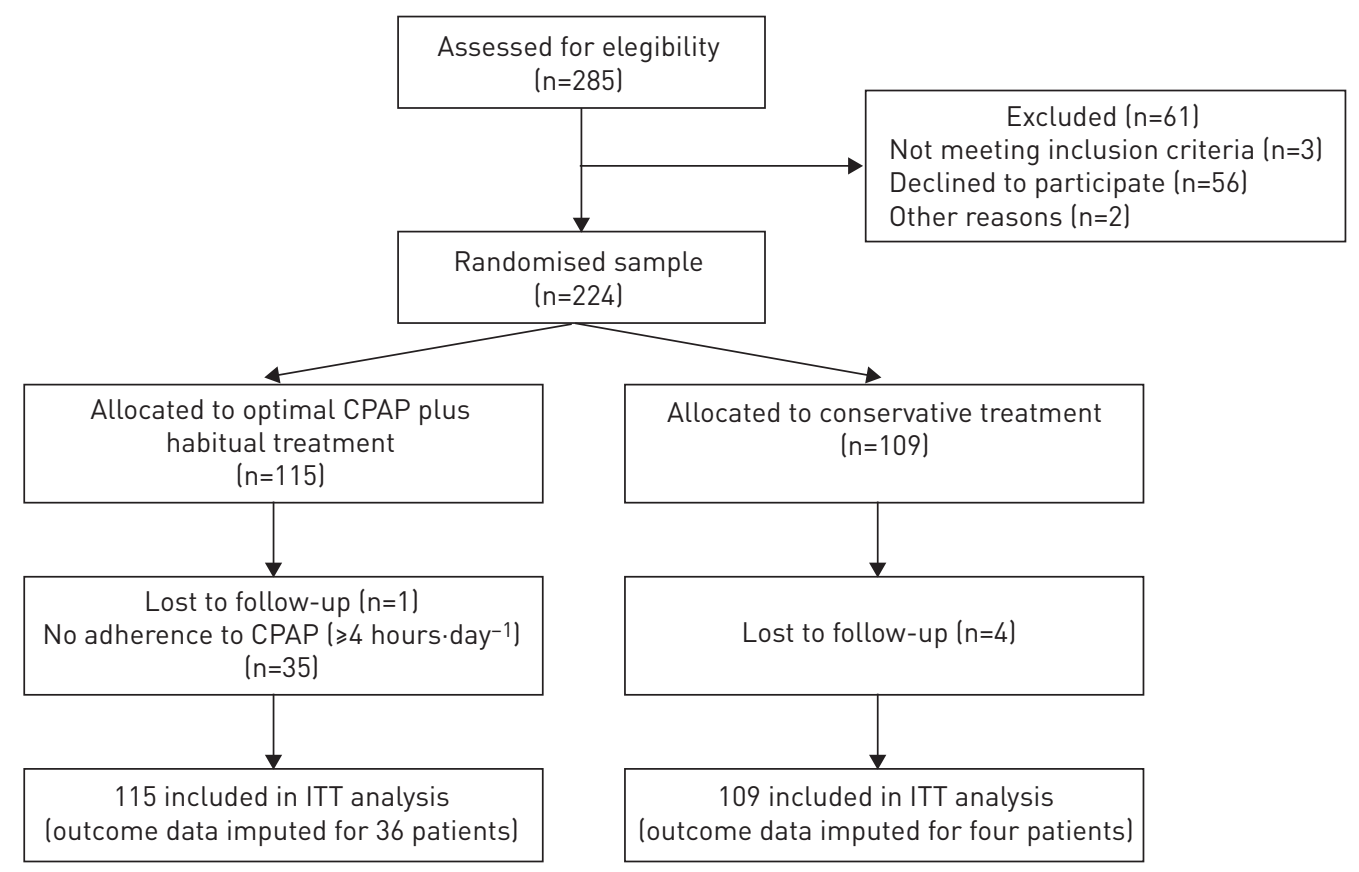

FIGURE 1 Flow-chart of the study. Intention-to-treat (ITT) analysis. CPAP: continuous positive airway pressure. 
TABLE 1 Baseline characteristics of randomised patients

\begin{tabular}{lccc} 
& All patients & CPAP treatment & No CPAP treatment \\
\hline Subjects & 224 & 115 & 109 \\
Age years & $75.5 \pm 3.9$ & $75.4 \pm 3.8$ & $75.6 \pm 4.0$ \\
Sex male & $153(68.3)$ & $73(63.5)$ & $80(73.4)$ \\
BMI $\mathbf{~ k g} \cdot \mathbf{m}^{-\mathbf{2}}$ & $32.9 \pm 6.3$ & $33.0 \pm 7.3$ & $32.8 \pm 5.1$ \\
BMI $\geqslant 30 \mathbf{~ g g} \cdot \mathbf{m}^{-\mathbf{2}}$ & $144(64.6)$ & $73(64.0)$ & $71(65.1)$ \\
Neck circumference cm & $42.6 \pm 3.6$ & $42.6 \pm 3.8$ & $42.7 \pm 3.5$ \\
ESS & $9.5 \pm 3.8$ & $9.6 \pm 4.0$ & $9.3 \pm 3.6$ \\
ESS $\geqslant \mathbf{1 0}$ & $84(37.7)$ & $43(37.4)$ & $41(38.0)$ \\
Sleep study, respiratory polygraphy & $152(68.5)$ & $76(66.7)$ & $76(70.4)$ \\
Past cardiovascular events & $61(27.2)$ & $31(26.9)$ & $30(27.5)$ \\
Systemic hypertension & $179(80.3)$ & $92(80)$ & $87(79.8)$ \\
Psychotropic drug use & $66(29.5)$ & $33(28.7)$ & $33(30.3)$ \\
AHI event $\mathbf{h}^{-1}$ & $50.4 \pm 14.9$ & $53.5 \pm 15.6$ & $47.2 \pm 13.4$ \\
Tsat90\% & $25.9 \pm 27.6$ & $29.8 \pm 30.6)$ & $21.6 \pm 23.1$ \\
ODI3\% & $45.3 \pm 18.7$ & $49.6 \pm 20.2$ & $40.3 \pm 15.4)$ \\
Central AHI & $2.2 \pm 5.7$ & $2.3 \pm 6.5$ & $2.1 \pm 4.7$ \\
Minimum $\mathbf{0}_{\mathbf{2}}$ saturation & $72.2 \pm 12.9$ & $70.7 \pm 12.5$ & $73.9 \pm 13.2$ \\
\end{tabular}

Data are presented as $\mathrm{n}$, mean \pm SD or $\mathrm{n}(\%)$. BMI: body mass index; ESS: Epworth Sleepiness Scale; AHI: apnoea-hypopnoea index; ODI: oxygen desaturation index; Tsat90\%: nighttime spent with an oxygen saturation below $90 \%$.

significant improvement in anxiety $(1.19(0.22-2.16) ; \mathrm{p}=0.016)$ and depression $(1.98(1.18-2.70) ; \mathrm{p}<0.001)$ scores from the HADS test.

Effect on cognitive function

CPAP resulted in a significant improvement in digit symbol score related to working memory $(-1.42$ $(-2.83--0.01), \mathrm{p}=0.047)$ and TMT A $(10(-4-34)$ versus $0(-16-11) ; \mathrm{p}=0.029)$. No differences were observed in the TMT B and digit span tests.

\section{Effect on office-based blood pressure levels}

Finally, no differences were observed in changes in either office-based systolic blood pressure $(-1$ versus $-0.1 \mathrm{mmHg} ; \mathrm{p}=0.9)$ or diastolic blood pressure $(-1.5$ versus $-1.2 \mathrm{mmHg} ; \mathrm{p}=0.2)$ measurements when comparing the CPAP and control groups.

\section{Discussion}

The main findings of this randomised clinical trial were that, in elderly patients with severe sleep apnoea, CPAP treatment achieves an improvement in all domains of quality of life measured by QSQ, including day-time and night-time symptoms and social and emotional domains. Furthermore, CPAP improves sleep-related symptoms, including choking, nightmares, nocturia and daytime hypersomnolence, depression and anxiety scores, as well as some neurocognitive tests related to working memory and executive functions. For the first time in the literature, this study shows that CPAP treatment is also effective in a specific group of elderly patients with severe sleep apnoea.

The majority of clinical trials on the effect of CPAP treatment in patients with sleep apnoea have been performed on middle-aged men, leaving some controversy about its effects on the elderly population [13 ]. Some observational studies have shown that elderly people with moderate-severe OSA have a poor prognosis in terms of cardiovascular mortality $[10,23]$, while other studies have shown the negative effect of an increase in sleep-disordered breathing on some neurocognitive functions in OSA $[11,24,25]$. Only a very limited number of studies are available, however, including just one series exploring the effect of CPAP treatment on elderly people $[11,26,27]$. A Spanish study including $>50000$ sleep tests in seven teaching hospitals concluded that almost $25 \%$ of patients sent to the sleep labs with clinical suspicion of OSA are aged $>65$ years and in $>65 \%$ of these patients CPAP treatment is prescribed without any clear scientific evidence [4]. This clinical trial has demonstrated that CPAP treatment has a positive effect on a specific group of elderly people (aged at least 70 years) sent to sleep labs for clinical suspicion of severe OSA with respect to quality of life, sleep-related symptoms, and some neurocognitive tests related to anxiety, depression and memory, even in an intention-to-treat analysis. 
TABLE 2 Changes in sleep-related symptoms between randomised groups in an intention-to-treat principle adjusted by basal measurements

\begin{tabular}{|c|c|c|c|c|c|c|c|c|c|c|c|}
\hline \multirow[t]{2}{*}{ Variables } & \multicolumn{4}{|c|}{ CPAP treatment $(n=115)$} & \multicolumn{4}{|c|}{ Conservative treatment ( $n=109)$} & \multirow{2}{*}{$\begin{array}{c}\text { Intergroup } \\
\text { difference } \\
(95 \% \mathrm{CI})\end{array}$} & \multirow[t]{2}{*}{$\mathbf{F}$} & \multirow[t]{2}{*}{ p-value } \\
\hline & Baseline & Follow-up & $\begin{array}{l}\text { Effect } \\
\text { size }\end{array}$ & $\begin{array}{l}\text { Intragroup } \\
\text { difference }\end{array}$ & Baseline & Follow-up & $\begin{array}{l}\text { Effect } \\
\text { size }\end{array}$ & $\begin{array}{l}\text { Intragroup } \\
\text { difference }\end{array}$ & & & \\
\hline Snoring & $110(95.7)$ & $20(17.4)$ & & $86(74.8)$ & 108 (99.1) & 99 (90.8) & & $2(1.8)$ & $84(73.0)(64.9-81.2)$ & & $<0.001$ \\
\hline Witnessed apnoeas & 90 (78.3) & $12(10.4)$ & & 73 (63.5) & $80(73.4)$ & 70 (64.2) & & $3(2.7)$ & $70(60.9)(52.0-69.8)$ & & $<0.001$ \\
\hline Nightmares & $24(20.9)$ & $10(8.7)$ & & $14(12.2)$ & 20 (18.3) & $26(23.9)$ & & $-8(-7.4)$ & $22(19.1)(11.9-26.3)$ & & $<0.001$ \\
\hline Choking & $39(33.9)$ & $3(2.6)$ & & 36 (31.3) & $29(26.6)$ & 25 (22.9) & & $0(0.0)$ & 36 (31.3) (22.8-39.8) & & $<0.001$ \\
\hline Nocturia & $2.23 \pm 1.40$ & $1.79 \pm 1.48$ & -0.31 & $0.44 \pm 1.46$ & $1.92 \pm 0.91$ & $1.90 \pm 0.91$ & -0.02 & $0.04 \pm 0.58$ & $0.282(0.001-0.563)$ & 1.98 & 0.049 \\
\hline ESS & $9.56 \pm 4.00$ & $5.94 \pm 3.41$ & -0.91 & $3.58 \pm 4.00$ & $9.33 \pm 3.62$ & $9.22 \pm 3.99$ & -0.03 & $0.10 \pm 2.85$ & $3.377(2.542-4.212)$ & 7.97 & $<0.001$ \\
\hline
\end{tabular}

TABLE 3 Changes in sleep-related quality of life (Quebec Sleep Questionnaire) between randomised groups in an intention-to-treat analysis adjusted by basal measures

\begin{tabular}{|c|c|c|c|c|c|c|c|c|c|c|c|}
\hline \multirow[t]{2}{*}{ Variables } & \multicolumn{4}{|c|}{ CPAP treatment $(n=115)$} & \multicolumn{4}{|c|}{ Conservative treatment $(n=109)$} & \multirow{2}{*}{$\begin{array}{c}\text { Intergroup } \\
\text { difference }(95 \% \mathrm{CI})\end{array}$} & \multirow[t]{2}{*}{$\mathbf{F}$} & \multirow[t]{2}{*}{ p-value } \\
\hline & Baseline & Follow-up & $\begin{array}{l}\text { Effect } \\
\text { size }\end{array}$ & $\begin{array}{l}\text { Intragroup } \\
\text { difference }\end{array}$ & Baseline & Follow-up & $\begin{array}{l}\text { Effect } \\
\text { size }\end{array}$ & $\begin{array}{l}\text { Intragroup } \\
\text { difference }\end{array}$ & & & \\
\hline \multicolumn{12}{|l|}{ QSQ quality of life } \\
\hline Hypersomnolence & $5.0 \pm 1.4$ & $5.9 \pm 1.3$ & 0.65 & $-0.90 \pm 1.37$ & $5.1 \pm 1.1$ & $5.3 \pm 1.2$ & 0.20 & $-0.20 \pm 1.05$ & $-0.612(-0.894--0.331)$ & 4.29 & $<0.001$ \\
\hline Diurnal symptoms & $4.5 \pm 1.5$ & $5.5 \pm 1.3$ & 0.69 & $-1.01 \pm 1.28$ & $4.7 \pm 1.3$ & $4.9 \pm 1.4$ & 0.13 & $-0.16 \pm 1.03$ & $-0.778(-1.049--0.506)$ & 5.64 & $<0.001$ \\
\hline Nocturnal symptoms & $4.3 \pm 1.2$ & $5.4 \pm 1.2$ & 0.98 & $-1.19 \pm 1.40$ & $4.3 \pm 1.2$ & $4.5 \pm 1.4$ & 0.17 & $-0.19 \pm 0.96$ & $-0.958(-1.249--0.668)$ & 6.50 & $<0.001$ \\
\hline Emotions & $5.2 \pm 1.4$ & $5.8 \pm 1.2$ & 0.41 & $-0.59 \pm 1.25$ & $5.2 \pm 1.3$ & $5.2 \pm 1.4$ & 0.01 & $-0.01 \pm 1.05$ & $-0.597(-0.864--0.331)$ & 4.41 & $<0.001$ \\
\hline Social interaction & $5.4 \pm 1.2$ & $6.1 \pm 1.2$ & 0.54 & $-0.68 \pm 1.31$ & $5.2 \pm 1.4$ & $5.5 \pm 1.3$ & 0.17 & $-0.23 \pm 1.31$ & $-0.546(-0.833--0.259)$ & 3.75 & $<0.001$ \\
\hline
\end{tabular}


a)

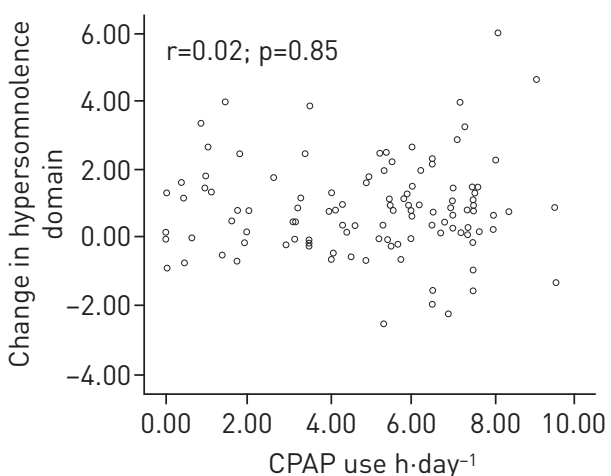

d)

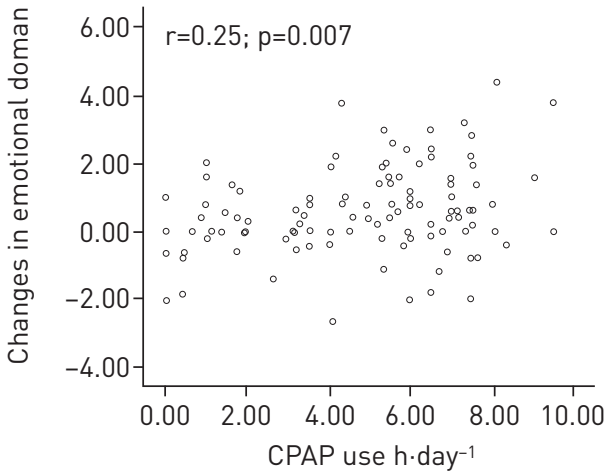

b)

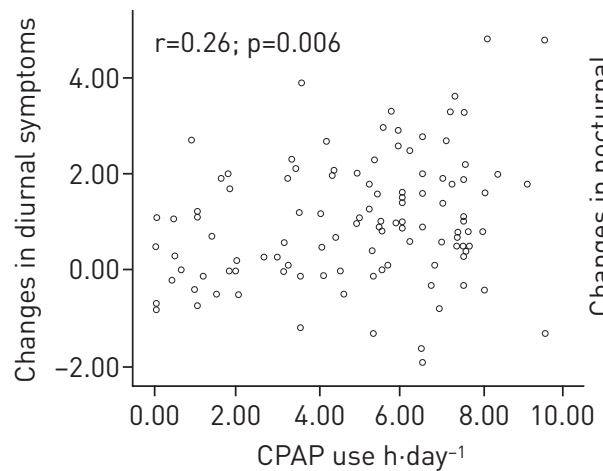

e)

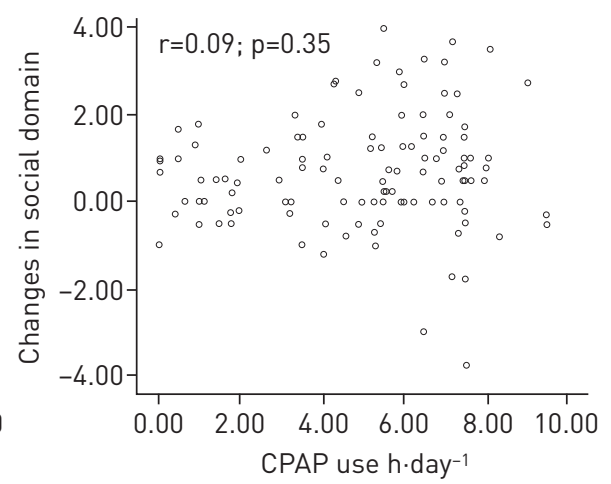

c)

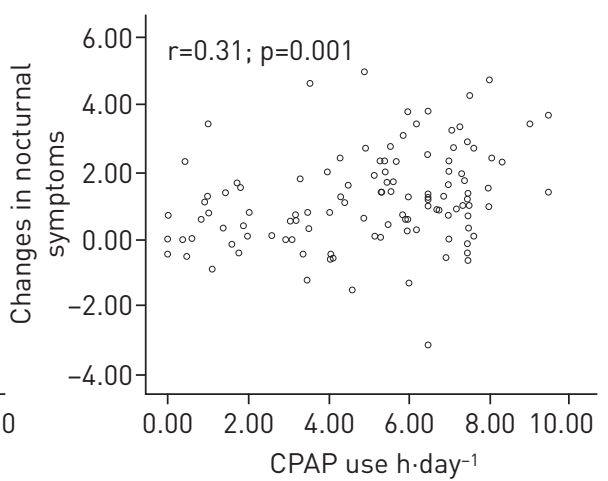

FIGURE 2 Pearson correlation between hours of continuous positive airway pressure (CPAP) use and changes in Quebec Sleep Questionnaire domains: a) hypersomnlence; b) diurnal symptoms; c) nocturnal symptoms; d) emotional; and e) social interactions.

It is worth noting that, although all the domains of QSQ presented a significant statistical improvement with CPAP compared with the control group, they did not reach the minimum clinically significant difference published by the authors of the QSQ [15]. However, it is important to bear in mind that the validation of the clinically significant differences of the QSQ was undertaken on a population with a mean age of 55 years, 20 years lower than that of the patients included in the present study. Therefore, as the condition of symptoms and social and emotional relationships can change significantly over 20 years, these minimum differences may not be applicable to the present study.

It is also important to mention that all measured sleep-related clinical symptoms improved with CPAP. Although it obviously seems logical that snoring and witnessed apnoeas would improve, the effect of CPAP on other clinical aspects related to OSA more likely to appear in elderly patients have been far less investigated (symptoms of presentation such as nightmares and nocturia). These symptoms are less specific in elderly patients as they can often be associated with other conditions, such as sleep alterations, prostate adenoma, medication or heart failure [28]. The present study shows, however, that when these symptoms appear in elderly patients with OSA they can be significantly associated with an excess of sleep-disordered breathing that can be corrected, or at least alleviated, by CPAP treatment. This also supposes that it is important not to forget these symptoms when recording the clinical history of patients with OSA, especially elderly ones. There was thus a statistically significant improvement in the value of the ESS, although once again this test has not been specifically validated in elderly populations and so the results must be approached with caution [29].

One important point is that we have not been able to find any excessive number of central respiratory events in our elderly series, thereby negating the old "myth" about the high prevalence of central respiratory events in the elderly. Other important results are related to the improvements in some neurocognitive functions in the CPAP group. One of the most evident results of the present study is probably the clear improvement in depression and anxiety symptoms measured by HADS. Some studies have found an association between anxiety and depression symptoms and sleep apnoea as one of the symptoms of presentation in elderly patients $[30,31]$. These results emphasise the need to take into account the presence of symptoms related to anxiety and depression unexplained by other causes in elderly patients with suspicion of OSA. Furthermore, some neurocognitive functions related to memory, executive function, 
TABLE 4 Changes in neurocognitive test between randomised groups in an intention-to-treat principle adjusted by basal measures

\begin{tabular}{|c|c|c|c|c|c|c|c|c|c|c|c|}
\hline \multirow[t]{2}{*}{ BP variables } & \multirow[t]{2}{*}{ Baseline } & \multicolumn{4}{|c|}{ CPAP treatment $(n=115)$} & \multicolumn{3}{|c|}{ Conservative treatment $(n=109)$} & \multirow{2}{*}{$\begin{array}{c}\text { Intergroup } \\
\text { differences (Cl 95\%) }\end{array}$} & \multirow[t]{2}{*}{$\mathbf{F}$} & \multirow[t]{2}{*}{ p-value } \\
\hline & & Follow-up & $\begin{array}{l}\text { Effect } \\
\text { size }\end{array}$ & $\begin{array}{l}\text { Intragroup } \\
\text { differences }\end{array}$ & Baseline & Follow-up & $\begin{array}{l}\text { Effect } \\
\text { size }\end{array}$ & $\begin{array}{l}\text { Intragroup } \\
\text { differences }\end{array}$ & & & \\
\hline HADS Anxiety & $6.88 \pm 4.40$ & $4.64 \pm 4.27$ & -0.51 & $2.28 \pm 4.31$ & $6.89 \pm 4.26$ & $5.77 \pm 4.21$ & -0.26 & $1.03 \pm 4.07$ & $1.192(0.225-2.160)$ & 5.90 & 0.016 \\
\hline HADS Depression & $6.90 \pm 4.47$ & $5.64 \pm 4.56$ & -0.28 & $1.29 \pm 3.46$ & $5.92 \pm 3.80$ & $6.79 \pm 4.31$ & 0.23 & $-0.93 \pm 2.76$ & 1.989 (1.180-2.799) & 23.47 & $<0.001$ \\
\hline Digit Span & $7.07 \pm 2.44$ & $7.37 \pm 2.53$ & 0.12 & $-0.30 \pm 1.88$ & $7.83 \pm 2.57$ & $7.90 \pm 2.69$ & 0.03 & $-0.04 \pm 1.81$ & $-0.076(-0.550-0.399)$ & 0.10 & 0.753 \\
\hline Digit Symbol & $18.04 \pm 12$ & $20.42 \pm 12.36$ & 0.20 & $-2.39 \pm 4.82$ & $20.88 \pm 12.93$ & $22.07 \pm 13.5$ & 0.09 & $-0.77 \pm 5.64$ & $-1.428(-2.837--0.019)$ & 3.99 & 0.047 \\
\hline
\end{tabular}


concentration and others can be affected in elderly patients with OSA, unlike younger patients, as has been observed in some studies [11,24-27]. There is only one clinical trial that has evaluated the improvement in some neurocognitive aspects in elderly patients under treatment with CPAP, although the included patients presented Alzheimer's disease [25] and so do not represent the overall group of elderly patients sent to sleep laboratories with suspicion of OSA. According to our results, there was a tendency towards improvement in all the neurocognitive tests in the CPAP group compared with the control group, although this difference was only statistically significant in the digit symbol and TMT-A, no significant changes were observed in the office-based blood pressure measurements in the CPAP group, in contrast with those found in some studies on elderly people, although in the present study regular blood-pressure measurements were taken rather than a 24-h ambulatory blood pressure monitor [32].

Finally, one important point that must be stressed is the degree of adherence to treatment found in elderly patients. In the present study around $70 \%$ of the patients tolerated CPAP for at least $4 \mathrm{~h}$ per night on average, which, despite some controversy in the literature in this respect, is similar to the percentages found in studies that include elderly patients $[33,34]$. In this sense, the present study showed a positive correlation between the hours of CPAP use and the improvement in some QSQ domains related to diurnal symptoms, nocturnal symptoms and the emotional sphere.

The most important limitation of the present study is probably that the control group is not blind to lack of treatment since a sham-CPAP was not used. However, in our opinion, a sham-CPAP is not a true placebo. Excessive air leaking and low air pressure (necessary to deliver a very low, non-effective pressure of $2-3 \mathrm{cmH}_{2} \mathrm{O}$ ) and persistence of symptoms, such as snoring or breathing pauses would make the patients realise that they are not receiving an effective treatment $[35,36]$. Another limitation is that some of the tests used have not been validated in populations exclusively comprising elderly people. So, there are no validations of the QSQ or the ESS in these populations, or of their minimum clinically significant differences; although the randomised nature of the study could minimise this limitation. Moreover, the main outcome of the study is a patient-reported outcome measure (QSQ) that is therefore open to reporting bias, although the study has a blind end point design. To minimise this bias this measure was collected by personnel interacting with patients.

In conclusion, according to our results, treatment with CPAP in elderly patients with severe OSA is effective in improving quality of life, sleep apnoea-related symptoms, symptoms of depression and anxiety, and some neurocognitive aspects. This confirms the notion that age should not be an impediment for treatment with CPAP in elderly patients with severe OSA. In this respect, all patients were offered the possibility of receiving CPAP treatment at the end of the study in their respective centres, in the light of the results of the present study and the positive effect of CPAP on the cardiovascular sphere seen by other studies in elderly patients with an AHI $\geqslant 30$ [10]. New studies are required to determine the effect of this treatment on elderly patients with mild or moderate OSA and to determine the AHI cut-off point at which elderly patients must be treated, taking into account the well-known increase in the prevalence of sleep-disordered breathing with age.

\section{Acknowledgements}

The members of the Spanish Sleep Network are as follows: Jose N. Sancho and P. Landete (Respiratory Department, Hospital Universitario San Juan, Alicante, Spain); A. Ferré (Respiratory Department, Hospital Vall Hebrón, Barcelona, Spain); MJ Masdeu (Respiratory Department, Hospital de Sabadell, Corporació Sanitaria Pac Tauli, Barcelona, Spain) M. Dalmases (Hospital Clinic, IDIBAPS, Barcelona, Spain); L. Zamora (L and B Román Hospital, General Universitario, Alicante, Spain); Erika Miranda-Serrano (Araba Health Research Unit, BioAraba, Osakidetza, Vitoria, Spain).

\section{References}

1 Engleman HM, Martin SE, Deary IJ, et al. Effect of continuous positive airway pressure treatment on daytime function in sleep apnoea/hypopnoea syndrome. Lancet 1994; 343: 572-575.

2 Jenkinson C, Davies RJ, Mullins R, et al. Comparison of therapeutic and subtherapeutic nasal continuous positive airway pressure for obstructive sleep apnoea: a randomised prospective parallel trial. Lancet 1999; 353: 2100-2105.

3 Ballester E, Badia JR, Hernandez L, et al. Evidence of the effectiveness of continuous positive airway pressure in the treatment of sleep apnea/hypopnea syndrome. Am J Respir Crit Care Med 1999; 159: 495-501.

4 Martínez-García MA, Amilibia J, Chiner E, et al. Apnea del sueño en individuos de edad avanzada. Actividad asistencial (2002-2008). [Sleep apnoea in elderly patients: care activity in Spain (2002-2008).] Arch Bronconeumol 2010; 46: 502-507.

5 Levy P, Pepin JL, Malauzat D, et al. Is sleep apnea syndrome in the elderly a specific entity? Sleep 1996; 19: Suppl. 3, s29-s38.

6 Martínez-García MA, Soler-Cataluña JJ, Román-Sánchez P, et al. Obstructive sleep apnea has little impact on quality of life in the elderly. Sleep Med 2009; 10: 104-111.

7 Duran J, Esnaola S, Rubio R. Obstructive sleep apnea-hypopnea in the elderly. A population-based study in the general population aged 71-100. Eur Respir J 2000; 31: Suppl. 16, 167s.

8 Bixler EO, Vgontzas AN, Ten Have T, et al. Effects of age on sleep apnea in men. Prevalence and severity. Am Respir J Crit Care Med 1998; 157: 44-148. 
9 Christensen K, Doblhammer G, Rau R, et al. Ageing populations: the challenges ahead. Lancet 2009; 374 1196-1208.

10 Martínez-García MA, Campos-Rodríguez F, Catalán-Serra F, et al. All-Cause and cardiovascular mortality in elderly patients with sleep apnea. Role of CPAP treatment. Am J Respir Crit Care Med 2012; 183: 909-1002.

11 Aloia MS, Ilniczky N, Di Dio P. Neuropsychological changes and treatment compliance in older adults with sleep apnea. J Psychosom Res 2003; 56: 549-553.

12 Consenso Nacional sobre el Síndrome de apneas-hipopnoeas durante el sueño. Arch Bronconeumol 2005; 41: $1-110$.

$13 \mathrm{Ng}$ SS, Chan TO, To KW, et al. Validation of Embletta portable diagnostic system for identifying patients with suspected obstructive sleep apnoea syndrome (OSAS). Respirology 2010; 15: 336-342.

14 Rechtschaffen A, Kales A. A manual of standardized terminology, techniques and scoring system for sleep stages of human subjects. Los Angeles, University of California, 1968.

15 Lacasse Y, Bureau MP, Sériès. A new standardised and self-administrated quality of life questionnaire specific to obstructive sleep apnoea. Thorax 2004; 59: 494-499.

16 Catalán P, Martínez A, Herrerón A, et al. Consistencia interna y validez de la versión española del cuestionario de calidad de vida "Québec Sleep Questionnaire" para apnea obstructiva del sueño. Arch Bronconeumol 2012; 48: $107-113$.

17 Lezack MD. Neuropsychological Assessment. 3rd Edn. New York, Oxford University Press, 1995.

18 Wechsler DA. Wechsler Adults Intelligence Scale (WAIS). Madrid, Tea Ediciones, 1976.

19 Zigmond AS, Snaith RP. The hospital anxiety and depression scale. Acta Psychiatr Scand 1983; 67: 361-370.

202007 European Society of Hypertension-European Society of Cardiology guidelines for the management of arterial hypertension. World Health Organization-International Society of Hypertension guidelines for the management of hypertension. J Hypertens 2007; 25: 1115-1187.

21 Masa JF, Jimenez A, Durán J, et al. Alternative methods of titrating continuous positive airway pressure. A large multicenter study. Am J Respir Crit Care Med 2004; 170: 1.218-1.224.

22 Cohen J. Statistical Power Analysis for the Behavioral Sciences. NewYork, Academic Press, 1969.

23 Muñoz R, Durán-Cantolla J, Martínez-Vila E, et al. Severe sleep apnea and risk of ischemic stroke in the elderly. Stroke 2006; 37: 2317-2321.

24 Kezirian EJ, Harrison SL, Ancoli-Israel S, et al. Behavioral correlates of sleep-disordered breathing in older men. Sleep 2009; 32: 253-261.

25 Yaffe K, Laffan AM, Harrison SL, et al. Sleep-disordered breathing, hypoxia, and risk of mild cognitive impairment and dementia in older woman. JAMA 2011; 306: 613-619.

26 Ancoli-Israel S, Palmer BW, Cooke JR, et al. Cognitive effects of treating obstructive sleep apnea in Alzheimer's disease: a randomized controlled study. J Am Geriatr Soc 2008; 56: 2076-2081.

27 Ferini-Strambi L, Baietto C, Di Gioia MR. Cognitive dysfunction in patients with obstructive sleep apnea (OSA): partial reversibility after continuous positive airway pressure (CPAP). Brain Res Bull 2003; 61: 87-92.

28 Endershaw YW, Jonson TM, Kutner MH, et al. Sleep-disordered breathing and nocturia in older adults. J Am Geriatr Soc 2004; 52: 957-960.

29 Chiner E, Arriero JM, Signes-Costa J, et al. Validación de la versión española del test de somnolencia Epworth en pacientes con síndrome de apnea de sueño. Arch Bronconeumol 1999; 35: 422-427.

30 Saunamaki T, Jehkonen M. Depression and anxiety in obstructive sleep apnea syndrome: a review. Acta Neurol Scand 2007; 116: 277-288.

31 Enright PL, Newman AB, Wahl PW, et al. Prevalence and correlates of snoring and observed apneas in 5,201 older adults. Sleep 1996; 19: 531-538.

32 Endeshaw YW, White WB, Kutner M, et al. Sleep-disordered breathing and 24-hour blood pressure pattern among older adults. J Gerontol A Biol Sci Med Sci 2009; 64: 280-285.

33 Weaver TE, Chasens ER. Continuous positive airway pressure treatment for sleep apnea in older adults. Sleep Med Rev 2007; 11: 99-111.

34 Weaver TE, Grunstein RR. Adherence to continuous positive airway pressure therapy: the challenge to effective treatment. Proc Am Thorac Soc 2008; 5: 173-178.

35 Hein H. Is sham CPAP a true placebo? Am J Respir Crit Care Med 2002; 165: 305

36 Schwartz SW, Cimino CR, Anderson WM. CPAP or placebo-effect? Sleep 2012; 35: 1585-1586. 